\title{
LA Persecución Penal de LAS PANIDILLAS EN EL SALVADOR
}

EDGARDO A. AMAYA CÓBAR*

\section{Introducción}

Agradezco a la Facultad de Derecho de la Universidad Centroamericana, a través de su decano, Dr. Manuel Aráuz, por la invitación a participar de este evento académico so bre las ciencias penales.

La problemática sobre el accionar criminal de las pandillas juveniles es uno de los temas con mayor auge en la agenda pública de países como El Salvador, Guatemala y Honduras. El enfoque sobre este tema incluso ha llevado a colocarlo como parte de los puntos de discusión en las instancias subregionales como en las regionales.

Lo cierto es que a pesar de la amplia difusión oficial y punitivo del problema de las maras en estos ámbitos, muy poco se conoce, o mucho se encubre, sobre las dimensiones e impactos reales del fenómeno en nuestras sociedades. Un resultado de este enfoque unidimensional da respuestas del mismo tipo, es decir, represión del fenómeno sin una comprensión y tratamiento de sus variadas aristas y matizaciones.

Lo anterior no obsta el hecho que las maras o pandillas juveniles en países como Guatemala, El Salvador y Honduras constituyan problemas de seguridad pública y que sus acciones contribuyen a incrementar el ciclo de violencia social que azota los mencionados países. 
No quisiera hacer de esta exposición un simple recuento de transformaciones o prácticas institucionales del sistema penal en El Salvador. El tema que se me ha encomendado coloca en el tapete de la discusión la cuestión sobre los alcances de la política criminal y del derecho penal respecto a los límites del Estado de Derecho y el uso o abuso de sus funciones simbólicas, por lo que trataré de mantener a lo largo de esta intervención este enfoque.

En esta exposición haré en primer lugar un breve marco de referencia sobre el fenómeno de las pandillas juveniles en El Salvador, en la segunda parte un recuento de las acciones tomadas en el caso salvadoreño para tratar este fenómeno, posteriormente una reflexión sobre la inclusión de esta temática en el marco más amplio de la discusión sobre la seguridad hemisférica y finalmente unas conclusiones.

\section{Marco de referencia}

Las pandillas juveniles no son un fenómeno espontáneo ni de "importación" como piensan algunos, son verdaderas expresiones de fenómenos sociales, básicamente urbanos, que se han producido en diferentes sociedades en diversos momentos históricos con mayor o menor intensidad. La historia de los Estados Unidos, por ejemplo, da cuenta de la existencia de múltiples pandillas en los crecientes núcleos urbanos de ciudades como Nueva York, Los Ángeles y Chicago, pandillas de gran componente étnico, como el caso de los pachucos o pandillas de jóvenes judíos o irlandeses.

Algunos antecedentes de investigación se pueden encontrar en el libro "Delinquent Boys" de Albert Cohen, publicado en el año 1955, donde acuñó la categoría "subcultura criminal” según la cual, los miembros de éstas, tendrían valores diversos y, a veces, opuestos a los de la cultura dominante. Cohen determinó que la delincuencia juvenil era más común en jóvenes varones de clases bajas, cuya expresión más común eran las pandillas. A pesar de las críticas, como la de dar por establecida una "cultura dominante" única, el esfuerzo más notorio de Cohen fue el de vincular la formación de pandillas juveniles con todo el contexto social circundante y no como fenómeno aislado, al mismo tiempo, desplazando la discusión desde el estándar ético o moral de sus miembros o su análisis exclusivo desde el punto de vista normativo (Baratta 2001: 68-70). 


\section{Revista de Derecho}

Por otro lado, el fenómeno de la organización de adolescentes y jóvenes en pandillas tampoco es un fenómeno nuevo en El Salvador como en otros países de la subregión, sin embargo, éstas tenían como características ser limitadas y referidas a territorios muy específicos (barrios, colonias), sin accionares delictivos relevantes, salvo riñas, consumo de drogas blandas, pequeños hurtos y actos de vandalismo. Estas agrupaciones prácticamente eran de tipo generacional y no tenían permanencia en el tiempo debido a la movilidad de sus miembros generada por la incorporación a las demandas de la vida adulta (empleo, estudios, establecimiento de familia).

Las pandillas juveniles empezaron a mutar en el contexto del conflicto armado de la década de los 80 por una conjunción de factores sociales concomitantes al conflicto, uno de ellos fue la ruptura del equilibrio entre la población rural y la urbana, trasladándose la primera a las ciudades huyendo de la violencia bélica, ampliando los niveles de pobreza urbana y los asentamientos urbanos precarios (cinturones de pobreza) con una casi nula intervención estatal, limitada a legalidad de los asentamientos y servicios básicos.

A esta transformación demográfica debe sumarse un pronunciado proceso migratorio, principalmente hacia los Estados Unidos. En ambos casos, estos cambios radicales de vida de amplios sectores poblacionales, dieron paso a generaciones de niños y niñas en situaciones sumamente contrastantes: padres o mayores que cambiaron completamente sus esquemas vitales por uno nuevo, más hostil para su supervivencia, invirtiendo sus energías en ésta, lo que iba en detrimento de los procesos de socialización de las nuevas generaciones.

Los diferentes estudios realizados sobre las pandillas o maras han destacado que el crecimiento urbano desordenado y masivo como un terreno fértil para el aparecimiento de las pandillas juveniles (Miranda y Smutt 1998: 19 y 20. También Santacruz y Concha-Eastman 2001: 34) Según estas autoras, la pobreza y escasez de servicios de determinados sectores urbanos propician la múltiple exclusión ${ }^{1}$ de sus habitantes y se

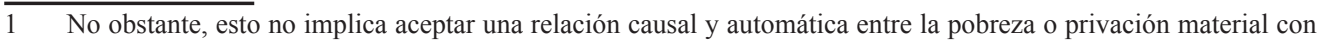
la delincuencia o la participación en pandillas, tal como lo expone el neorrealismo de izquierda: "La privación relativa es el exceso de las expectativas por sobre las oportunidades. La importancia de este concepto es que se aparta de las ideas simplistas que tratan de relacionar el descontento y la violencia colectiva con niveles de privación absoluta. La relación que existe entre la privación relativa y la marginación política resulta crucial para comprender los disturbios y la violencia colectiva. No es probable que la marginación política cause disturbios a menos que exista además una sensación de frustración que surja de la existencia de privación relativa." (Young y Lea 2001: 223) 
constituye como el entorno de vida de los jóvenes, que buscan escapar de esta realidad. Santacruz y Concha-Eastman (2001: 34) por su parte, señalan la inexistencia o privatización de los espacios públicos, por lo que los espacios de compartimentación social y relacionamiento se encuentran cerrados, especialmente para los y las jóvenes.

A principio de la década de los 90, las pandillas juveniles, ya se perfilaban como un problema social que comenzaba a tener atención por la ciudadanía. En 1993, la Fiscalía General de la República, reportó la existencia de 236 pandillas, de las cuales 185 se encontraban en la ciudad capital (Miranda y Smutt 1998: 32) También a finales de los ochenta se visibilizaron las denominadas "pandillas estudiantiles", cuyo referente era la pertenencia a determinados centro educativo. A inicios de los años noventa, este tipo organización pandilleril generaba importantes niveles de violencia por las disputas entre los diferentes grupos escolares, conflictos que en diversas ocasiones deban saldos graves como homicidios y lesiones.

En esta época se da el aparecimiento de agrupaciones identificadas con pandillas latinas asentadas en la ciudad de Los Ángeles, California, estado con una importante población de origen salvadoreño, básicamente la pandilla Barrio 18, cuyo nombre deriva del número de la calle de origen y sobre la que ejercen control en la ciudad angelina y la Mara Salvatrucha o MS 13, cuyo nombre destaca el origen salvadoreño de sus integrantes originarios, a diferencia de las múltiples nacionalidades mesoamericanas, incluida la salvadoreña, integradas en la rival Barrio 18 de Los Ángeles.

No se tiene conocimiento preciso sobre la existencia de procesos de integración o mutación de las pandillas existentes en El Salvador hacia estas nuevas modalidades y agrupaciones. En el año 1993, la Policía Nacional Civil distinguía cuatro tipos de agrupaciones de maras: las de estudiantes, las de comunidad, las de colonias y las provenientes de Estados Unidos ${ }^{2}$. Algunas agrupaciones mantuvieron su identidad, y persisten con algún nivel de presencia. Sin embargo, el efecto aglutinador del modelo de pandilla latina californiana, es sin duda, un verdadero fenómeno de organización que se ha manifestado en su crecimiento y cobertura territorial, constituyéndose en el modelo de mara dominante.

$2 \quad$ El Diario de Hoy, 15 de septiembre de 2003 (Citado por Miranda y Smutt 1998: 27) 


\section{Revisla de Perecho}

En la actualidad, la MS 13 y la Mara 18 son las dos agrupaciones más grandes y visibles del país.

Datos policiales del año 2003, establecían un estimado de 10 mil 200 miembros de pandillas, los cuales estarían repartidos en fragmentos denominados clicas, ubicados mayoritariamente en los 21 municipios donde se comete el 63\% de los delitos denunciados. La MS 13, tendría 170 clicas, el Barrio 18, 102 clicas y otras pandillas tendrían 37 agrupaciones dispersas en el país. Cada clica tendría entre 10 y 30 miembros.

La principal manifestación de la situación de las pandillas en los últimos diez años, ha sido su permanente crecimiento y el consecuente crecimiento del impacto y visibilidad del fenómeno y sus expresiones violentas.

En las primeras investigaciones relativas a las pandillas realizadas en los años noventa, aunque se constataba que los miembros de pandillas ejercían actividades delincuenciales, básicamente, las derivadas del ejercicio de la violencia hacia otras pandillas (homicidios, lesiones, amenazas, etc.) así como delincuencia de tipo patrimonial (hurtos y robos) Sin embargo, en el año 2004 y comparando los hallazgos de investigaciones previas con datos recientes Carranza (2004) concluye que los niveles de participación criminal de los miembros de pandillas se ha incrementado considerablemente con el tiempo y existen evidencias de que grupos de las diferentes maras estarían vinculándose con el crimen organizado como "subcontratados" para actividades específicas, como seguridad, resguardo, o incluso, actividades operativas como ejecución de robos y, en alguna ocasión, secuestros.

Otro tema importante es que grupos de pandillas se estarían incorporando al mercado de droga como "distribuidores minoristas" (Carranza 2004: 19) traficando pequeñas cantidades como forma de obtención de recursos para la clica. Debe aclararse que los estudios citados no concluyen que las actividades relacionadas con el mercado de la droga sean significativas en la vida de las maras, sino más bien, enfatizan que estos son casos aislados y decisiones de grupos específicos dentro de las pandillas, en este sentido, las atribuciones hechas por algunas notas periodísticas en el sentido que las pandillas forman parte del crimen organizado y del narcotráfico no son absolutas y los datos mostrados indican la necesidad de matizar tales afirmaciones. 


\section{La respuesta penal a la cuestión de las maras}

La sociedad salvadoreña se vio inmersa en la segunda mitad de 2003 en la discusión sobre el denominado problema de las maras o pandillas juveniles. La atención a este tema acaparó importantes espacios de la vida política y de los medios de comunicación en el país.

Esta discusión dio inicio con el inicio del Plan Mano Dura, el cual, fue un esfuerzo de focalización policial en sectores afectados por la actividad de grupos pandilleros o maras, cuyo fin es la detección y captura masiva de miembros de estas organizaciones. Este plan inició como una estrategia policial en julio de 2003 y simultáneamente se impulsó un proceso de reforma y adecuación normativa para este plan, el cual ha comprendido la realización de enmiendas al Código Penal y al Código Procesal Penal, así como la creación de una ley especial, la Ley Antimaras.

Sin embargo, ya antes del Plan Mano Dura, ya se habían desarrollado una práctica desde las instituciones de seguridad pública, tendiente a la persecución y captura de miembros de pandillas. El discurso oficial a lo largo de 2003 se había orientado hacia estos grupos juveniles como problema de seguridad. Ya en enero, el entonces director de la PNC, Mauricio Sandoval había manifestado que las pandillas eran un tema prioritario debido a que, según estadísticas policiales, éstas cometían el $40 \%$ de los delitos registrados.

El proceso legislativo que dio vida a la Ley Antimaras, como su implementación, fueron fuertemente apoyados desde el Órgano Ejecutivo y muy criticados desde sectores académicos, de derechos humanos y parte de la oposición política, por los retrocesos que en materia de derechos humanos y derecho penal constituyen estos instrumentos ${ }^{3}$. Este proceso se vio acompañado de un gran gasto en publicidad por parte del Ejecutivo por la cual se han comprado una importante cantidad de espacios en diferentes medios de comunicación para influir en la opinión pública a favor de esta iniciativa gubernamental.

El proceso de discusión sobre las maras se basó prácticamente en una discusión sobre la penalización del fenómeno. Este nivel de discusión,

3 "El Director de la Policía, insistió en que la mayoría de la población del país está de acuerdo con el Plan Mano Dura, y aseguró que la corporación policial necesita leyes más fuertes para combatir las pandillas. Criticó a los "intelectuales", que según él "no quieren aceptar que una ley Antimaras sería lo mejor para el país." La Prensa Gráfica, 31 de agosto de 2003. Pág. 14. 
obtuso, limitado, era y es consecuencia natural de la concepción gubernamental de la situación de violencia y seguridad, que hace una confusión conceptual entre delincuencia y violencia, que incita este tipo de respuestas desde el ámbito normativo (Amaya, 2002: 38) y a la facilidad de obtener réditos políticos por quienes las promueven 4 .

Como consecuencia de esta confusión conceptual y reduccionista del problema, ergo, “(...) [la] solución se encuentra en la mayor aplicación de violencia institucional, ampliando las facultades de las agencias de seguridad y justicia, en un esquema en donde la violencia es tanto, un problema, como una solución a aplicar" (Amaya y Palmieri, 2000: 82; en este sentido también Amaya 2003a) En razón del mencionado reduccionismo, podemos decir, que estamos en presencia de una debate ideologizado ${ }^{5}$.

Debe destacarse la forma de intervención hacia el problema de las maras: hecha de manera exclusiva desde la política de seguridad pública gubernamental, que favorece fundamentalmente, el ejercicio de la coerción, especialmente desde la institución policial y en los últimos días, con la participación del ejército, en violación al ordenamiento constitucional que dispone la separación de las labores de seguridad pública, propias de la Policía, de las de defensa nacional, constitucionalmente encomendadas las Fuerzas Armadas.

La política de seguridad pública gubernamental, parte de una concepción de seguridad sinónima de orden o ausencia de delitos o conflictividad, que desplaza a la seguridad como derecho humano para todos los habitantes. Consecuencia de este desplazamiento de la seguridad como derecho y su sobredimensionamiento como facultad coercitiva estatal (FESPAD 2002; Amaya 2003), causa un efecto de la política gubernamental tal, que en la economía de la seguridad, unos ciudadanos ("ciudadanos honrados") son sujetos de protección frente de otros que son considerados como objetos de las políticas de seguridad (niños y jóvenes pobres, marginales, excluidos), siendo sus primeros afectados y no sus beneficiarios (Baratta 1999).

Por otro lado, legislativamente se ha dado un favorecimiento de medidas punitivas antes que la creación de otras alternativas. El proceso legislativo

4 Paul Chevigny (2002: 61) argumenta que estas iniciativas de endurecimiento -o populismo punitivo cómo lo denomina $\_$permiten a los políticos y gestores de seguridad mostrar una imagen de fortaleza y desviar interesadamente los enfoques del público.

5 Atendemos a la concepción de Ignacio Ellacuría que distingue a la ideología como un mecanismo de encubrimiento o tergiversación de la realidad. 
ha contribuyó a un proceso de inflación legislativa y a la ampliación de intervención punitiva estatal. De esta manera, el derecho penal, traducción normativa del poder penal del Estado, tradicionalmente pensado como última instancia de intervención frente a la conflictividad, se vio devaluado en tal calidad.

La Ley Antimaras fue impugnada y decretada inconstitucional por la Corte Suprema de Justicia en el mes de abril de 2004, pocos días antes que dicha ley perdiera vigencia.

La sentencia de la Sala de lo Constitucional, aunque tardía, aportó elementos valiosos en tanto estableció una visión constitucional del derecho penal, el cual comprendía el principio de lesividad, el de culpabilidad y de legalidad, así como el principio de igualdad y no discriminación de las personas y la dignidad humana. En el ámbito procesal estableció que la persecución penal del estado es de exclusiva competencia de la Fiscalía General Pública.

Para los jueces que señalaron las graves contradicciones de la ley con la Constitución, la sentencia significó un claro respaldo al control de constitucionalidad que realizaron, deslegitimando los señalamientos de negligencia judicial realizados por el ejecutivo.

Sin embargo, la Asamblea decretó una nueva ley con vigencia por 90 días, denominada "Ley para el Combate de las Actividades Delincuenciales de Grupos o Asociaciones Ilícitas Especiales", la cual fue aprobada sin discusión legislativa amplia y tuvo una vigencia de noventa días (1 de abril de 2004 a 29 de junio de 2004).

Esta segunda ley fue igualmente criticada que su antecesora, debido a que consistía en una versión editada de la primera y mantenía algunos de los aspectos violatorios más importantes de la primera como la "habilitación de menores", mediante la cual, se podría, previo peritaje, determinar si un menor podía ser juzgado como adulto. Esta ley no fue objeto de impugnación constitucional dado que muy posiblemente, cumpliría su tiempo de vigencia antes de que la Sala de lo Constitucional pudiera pronunciarse y por otro lado, porque el control de constitucionalidad ya era ejercido por los jueces mediante el control difuso que les faculta la Carta Magna en el artículo 185, mediante el cual rechazaron mayoritariamente los casos ingresados bajo la legislación contra las 
pandillas. De menos conocimiento del público fueron las peticiones de muchos fiscales desestimando estos casos en las audiencias iniciales del proceso.

En la revisión del estado de la Convención sobre los Derechos del Niño por el Comité de la materia de la ONU, en el caso de El Salvador, se estableció la contradicción de la legislación especial antimaras con el diseño de derechos dado por la Convención, generando un sistema dual de justicia juvenil, por esta razón, el Comité se pronunció expresamente por la derogatoria de la legislación antimaras (Committé on the rights of the Child 2004: 13).

Para el 17 de julio de 2004, la PNC reportó haber capturado en el marco del Plan Mano Dura, 17,162 personas, de las cuales, el 91\% no continuaron por ser los casos objeto de liberación en las fases iniciales del proceso penal. De los liberados, un $84 \%$ fue por sobreseimiento definitivo y el otro $7 \%$ lo fue por sobreseimiento provisional, debido a falta de pruebas. Un $5 \%$ de los capturados fue sometido a proceso, pero aparentemente por otras figuras delictivas diferentes a las estipuladas por las leyes antimaras ${ }^{6}$.

Debido a que una amplia mayoría de casos fueron sobreseídos por la inaplicación judicial de las leyes antimaras por ser considerada inconstitucional, se puede afirmar que todas esas capturas, desde la óptica de la doctrina de los derechos humanos, pueden ser calificadas como arbitrarias no solo por sus infracciones constitucionales, sino también por la sistematicidad de su aplicación.

La falta de resultados en sedejudicial, generó una campaña depresión, con tintes intimidatorios, hacia los jueces por parte del Ejecutivo, quienes los acusaban de sabotear la iniciativa, ello implicó un fuerte enfrentamiento interorgánico y un desgaste de las instituciones (FESPAD 2004).

Pese a las presiones políticas, el apoyo popular obtenido a las iniciativas contra las pandillas y el despliegue del aparataje simbólico del derecho penal en torno de la ley antimaras, éstas políticas de mano dura, lejos de intervenir en la problemática de la violencia de manera positiva,

$6 \quad$ El 4\% restante, al momento de la nota citada, se encontraba esperando audiencia en sede judicial. Los datos fueron tomados de la sección dedicada al Plan Mano Dura de la página de la Policía Nacional Civil (www.pncelsalvador. gob.sv) 
incrementaron el desgaste y debilidad de las instituciones de justicia, incluida la policía, y su principal efecto perverso ha sido el incremento, en los años en que se implementaron las políticas de mano dura, de los homicidios intencionales, convirtiéndose en la actualidad una de las principales demandas ciudadanas de seguridad.

Aunque las leyes antimaras ya no existen, la focalización de las políticas de seguridad pública sobre éstas sigue vigente y se realiza mediante la aplicación de calificaciones jurídicas "comodín”, es decir, mediante tipos penales como la "resistencia" o "agrupaciones ilícitas" del Código Penal. Es decir, en esencia, las leyes especiales y temporales previas, se redujeron a uno o dos artículos del código penal, pero cobraron permanencia en su vigencia.

\section{La política criminal y las políticas de seguridad en el contexto actual}

Desde hace varios años, en especial desde el once de septiembre de 2001, la región ha sufrido transformaciones en sus sistemas de seguridad, básicamente como seguimiento o reacción a la agenda norteamericana contra el terrorismo y sus intereses geopolíticos actuales.

Esta visión de la seguridad, coincidente con la denominada seguridad hemisférica de la OEA, en el enfoque multidimensional de la seguridad por el cual, dentro de esta categoría, se agregan nuevas amenazas y desafíos. Sin embargo, la debilidad de esta nueva agenda de seguridad es que enfrenta estas nuevas amenazas o desafíos con instrumentos tradicionales de seguridad, es decir mediante las policías y los ejércitos, lo que ha promovido la securitización de las políticas públicas en el tratamiento de diversos fenómenos sociales como las maras y la migración, los que aborda como problemas de seguridad y no como un problema social o de desarrollo. El uso distorsionante de estas nuevas amenazas, amorfas, son ahora, el nuevo comodín que justifica la creación de nuevos enemigos internos o transnacionales y por esta vía, justificar su combate.

El impacto de estas políticas de seguridad ha tenido un efecto negativo y erosionante de la institucionalidad de nuestros países, mediante la neo militarización de diversos aspectos sociales, un favorecimiento a la represión de la conflictividad social y un debilitamiento de las instituciones del sistema penal en su capacidad de control de estas políticas de seguridad. 


\section{Revisla de Derecho}

Estas mismas políticas han generado el impulso de una visión del derecho penal securitista o, como se ha dicho en estas jornadas, del enemigo.

\section{Conclusión}

En la actualidad existen dos tendencias de comprensión del problema de las pandillas claramente opuestas, por un lado, las que comprende este fenómeno como una expresión criminal y por esta vía, favorecen la intervención punitiva del estado contra estas agrupaciones como única respuesta posible y aquellos que ven a las pandillas como un fenómeno social complejo y multidimensional.

Lo que la experiencia salvadoreña ha demostrado es que el abordaje exclusivamente punitivo del fenómeno, ha generado graves efectos perversos como el incremento de la violencia de estos grupos y la mejora de sus capacidades de organización.

Lo inmanejable del problema de las pandillas desde una óptica reduccionista como la punitiva, ha generado nuevos brotes anómicos tales como las ejecuciones sumarias de pandilleros y aparecimiento con mayor fuerza de grupos de exterminio y por otro lado, una mayor respuestas violenta de los pandilleros hacia autoridades del estado.

Es necesario un abordaje serio, desapasionado y objetivo sobre las pandillas, que pueda dar formas de intervención alternativas para minimizar el creciente impacto de éstas en el ciclo de la violencia de los países afectados.

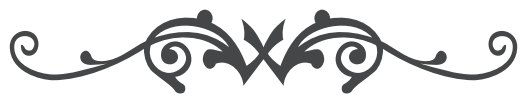

